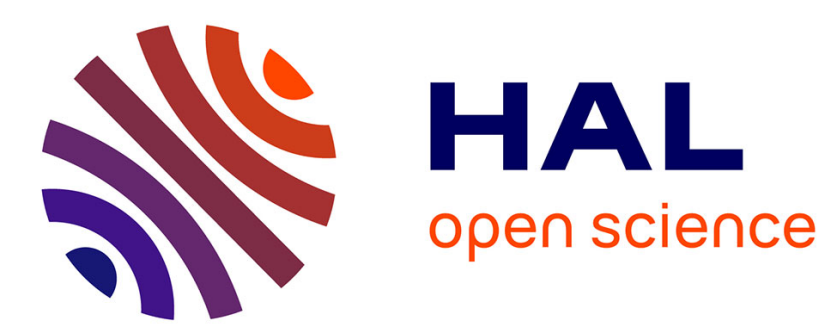

\title{
Study of thermal effects associated with crack propagation during very high cycle fatigue tests
}

Nicolas Ranc, Danièle Wagner, Paul C. Paris

\section{To cite this version:}

Nicolas Ranc, Danièle Wagner, Paul C. Paris. Study of thermal effects associated with crack propagation during very high cycle fatigue tests. Acta Materialia, 2008, 56 (15), pp.4012-4021. 10.1016/j.actamat.2008.04.023 . hal-00283642

\section{HAL Id: hal-00283642 \\ https://hal.science/hal-00283642}

Submitted on 17 Jan 2018

HAL is a multi-disciplinary open access archive for the deposit and dissemination of scientific research documents, whether they are published or not. The documents may come from teaching and research institutions in France or abroad, or from public or private research centers.
L'archive ouverte pluridisciplinaire HAL, est destinée au dépôt et à la diffusion de documents scientifiques de niveau recherche, publiés ou non, émanant des établissements d'enseignement et de recherche français ou étrangers, des laboratoires publics ou privés. 


\title{
Study of thermal effects associated with crack propagation during very high cycle fatigue tests
}

\author{
N. Ranc ${ }^{\mathrm{a}, *}$, D. Wagner ${ }^{\mathrm{b}}$, P.C. Paris ${ }^{\mathrm{c}, \mathrm{d}}$ \\ ${ }^{a}$ LMSP, UMR CNRS 8106, Arts et Métiers-ParisTech, 151 Boulevard de l'Hôpital, 75013 Paris, France \\ ${ }^{\mathrm{b}}$ LEEE, EA 387, Université Paris $X$ - Nanterre, 50 rue de Sévres, 92410 Ville d'Avray, France \\ ${ }^{\mathrm{c}}$ Washington University, Mechanical and Aerospace Engineering Department, St Louis, MO 63130-4899, USA \\ ${ }^{\mathrm{d}}$ LAMEFIP, EA 2727, ENSAM-Polytech, Esplanade des Arts et Métiers, 33405 Talence Cedex, France
}

\begin{abstract}
This paper studies the thermal effects associated with the propagation of a fatigue crack in a gigacycle fatigue regime. Ultrasonic fatigue tests were carried out on a high-strength steel. The temperature fields measured by infrared thermography show a significant and very local increase in the temperature just before fracture. In order to better understand these thermal effects and to make a connection with the initiation and the propagation of the fatigue crack, a thermomechanical model is developed. The fatigue crack is modeled by a cir-cular ring heat source whose radius increases with time. The numerical resolution of the thermal problem allows determination of the time evolution of the temperature fields in specimens and shows a good correlation with experiment. These results provide experimental proof that in a very high cycle regime, the propagation stage of the crack constitutes a small part of the lifetime of the specimen.
\end{abstract}

Keywords: Very high cycle fatigue; Thermal effects; Temperature; Infrared pyrometry

\section{Introduction}

In the lifetime of mechanical structures, many elements can be loaded beyond $10^{7}$ cycles. Consequently, there is interest in very high cycle fatigue (VHCF) regimes or gigacycle fatigue regimes. For several years, many researchers have thus been exploring these VHCF regimes [1]. It has been found and highlighted that the fracture mechanisms associated with VHCF are partially different from those known more classically in high cycle fatigue (HCF). For example, it was shown that fatigue failure can occur at more than $10^{7}$ cycles and at stress levels below the conventional HCF limit. Moreover, it has also been shown that in a VHCF regime, and particularly in high yield strength steels, the fracture does not occur on the surface but rather internally in the material [2]. This fracture initiation is

\footnotetext{
${ }^{*}$ Corresponding author.

E-mail address: nicolas.ranc@paris.ensam.fr (N. Ranc).
}

characterized by the formation of a fish eye. The various mechanisms are not currently very well known because of experimental difficulties, such as very long test duration. In the gigacycle fatigue regime, testing is carried out at ultrasonic frequencies, in order to save time and to perform $10^{9}$ cycles in a reasonable time. This means that the thermal dissipation is higher than at low frequencies. One question is also of interest: is it possible to use the temperature growth to understand the fatigue initiation in the very high cycle regime?

Many authors have been interested in using temperature measurements at the beginning of the fatigue test (about 10,000 cycles) to understand, for example, the effect of the stress amplitude on the temperature rise [3-7] and thermal dissipation [8-10]. These studies were carried out in the $\mathrm{HCF}$ regime and not in the very VHCF regime because not many authors were really interested in the fracture stage.

Fish eye formation, i.e. crack propagation, inside the material in the gigacycle fatigue regime is related to a local 
increase in the temperature. For this reason we have studied the temperature field, the thermal dissipation and the mechanical damage during VHCF tests.

The main objective of this paper is to use thermal measurement during fish eye formation in ultrasonic testing in order to understand better the fracture mechanisms in the VHCF regime. According to the experiments the temperature growth is small in aluminium alloys, and therefore development of the fish eye is difficult to observe. Consequently high-strength steel has been chosen for this study in order to obtain good experimental conditions.

First we will detail the temperature field measured during two VHCF tests. In order to understand these temperature fields, a model is proposed of the thermal effects associated with fatigue crack propagation. Finally, a comparison is made of the experimental results and the temperature fields obtained with the model, and crack initiation is also discussed.

\section{Experimental study}

In this study, we carried out VHCF tests on a steel with $0.2 \% \mathrm{C}$ and low alloyed with $\mathrm{Mn}, \mathrm{Cr}$ and $\mathrm{Si}$, each with less than $1 \%$. This steel is quenched and tempered in order to obtain a yield stress of about $2000 \mathrm{MPa}$. Its microstructure is martensitic with some residual austenite. In order to carry out tests beyond $10^{8}$ cycles in reasonable times, an ultrasonic machine is used which allows high-frequency loading (about $20 \mathrm{kHz}$ ). The geometry of the specimen, which is shown in Fig. 1a, is axisymmetric. The radius of the test section, noted $R_{1}$, is equal to $1.5 \mathrm{~mm}$. The radius of the specimen ends was made equal to $5 \mathrm{~mm}$. In order to obtain a resonant vibration frequency of the specimen at $20 \mathrm{kHz}$, the lengths $L_{1}$ and $L_{2}$ were chosen as 16 and $10 \mathrm{~mm}$, respectively. The specimen is fixed at one of the ends of the horn of the ultrasonic machine. The experimental device is represented in Fig. 1b. The specimen is loaded in tension compression $\left(R=\frac{\sigma_{\min }}{\sigma_{\max }}=-1\right)$. The ultrasonic fatigue technique is not detailed in this paper; however, more information can be found in Ref. [2], for example.

During a cyclic loading, a homogeneous increase in specimen temperature is observed. Three different types of heat sources can be noted. The first is associated with the thermoelastic coupling [11]. As this effect is reversible, it generates an oscillation of the temperature at each cycle. The amplitude of this oscillation is in general very low (about $0.6{ }^{\circ} \mathrm{C}$ in our case). The second is associated with plastic dissipation of the mechanical energy into heat. This phenomenon is not reversible and the dissipated energy accumulates for each cycle. In our case, this effect is generally higher than that generated by the thermoelastic coupling (a few tens to a few hundred degrees). Lastly, in some materials, we can observe an exothermic phase transition during strain which creates an additional heat source (latent heat associated with a martensitic transformation, for example) [12].
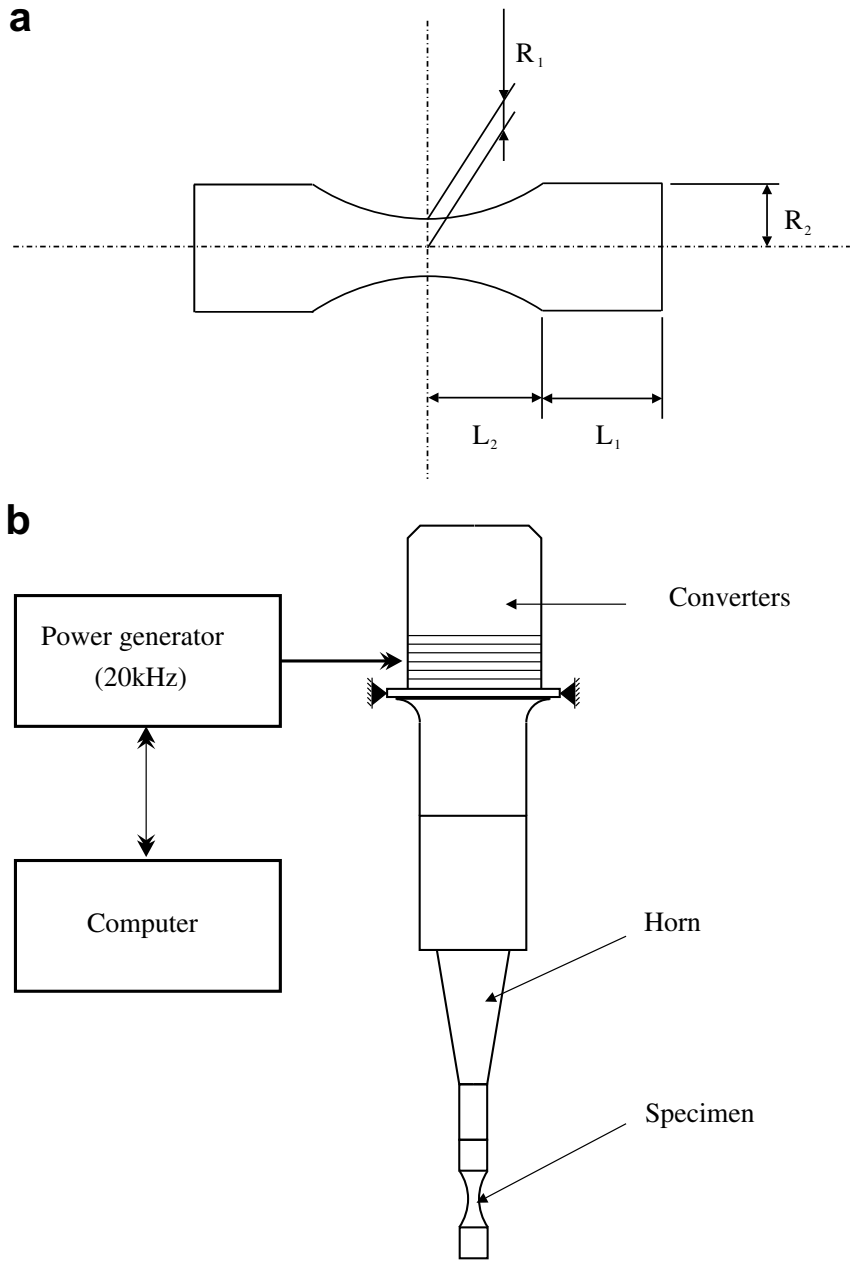

Fig. 1. Ultrasonic fatigue test: (a) geometry of the specimen and (b) ultrasonic fatigue machine.

In the experiment, the specimen is cooled by an air circulation at $20^{\circ} \mathrm{C}$, in order to limit its heating. Thanks to the forced convection on the specimen surface, we can ensure that the average temperature of the specimen during the test is between 200 and $300^{\circ} \mathrm{C}$. If we overestimate the convection coefficient $h$ to $200 \mathrm{~W} \mathrm{~m}^{-2} \mathrm{~K}^{-1}$, we can calculate the Biot number $B i=\frac{h R_{1}}{2 \lambda}$ associated with the specimen. If we choose a thermal conductivity $\lambda=52 \mathrm{~W} \mathrm{~K}^{-1} \mathrm{~m}^{-1}$, we find a Biot number of $2.9 \times 10^{-3}$. As this number is small compared with unity, it is considered that the temperature is homogeneous over the specimen radius, in spite of the air circulation.

In order to measure the temperature on the specimen surface, and therefore to detect the associated plastic deformation, an infrared camera is used. The spectral range of this camera is in the near-infrared domain (between the wavelengths 3.7 and $4.8 \mu \mathrm{m}$ ). The aperture time is $10 \mu \mathrm{s}$ and the acquisition frequency is 10 or $100 \mathrm{~Hz}$. A $50 \mathrm{~mm}$ focal length objective permits a spatial resolution of $0.12 \mathrm{~mm}$ per pixel. The entire width of the gage section can be visualized thanks to the large size of the matrix (64 $\times 80$ pixels). The camera is calibrated on a black body 
in the temperature range $50-400{ }^{\circ} \mathrm{C}$. The specimen was covered with a fine coating of a strongly emissive black paint in order to limit the errors associated with emissivity of the surface. This paint resists temperatures of up to $600^{\circ} \mathrm{C}$.

Two tests were carried out. Fig. 2 shows the temperature evolution in the center of the useful part of the specimen during the first fatigue test with a stress amplitude of $\Delta \sigma$ of $315 \mathrm{MPa}$. This test was stopped at approximately $10^{7}$ cycles without fracture. In Fig. 2, we can see an initial increase in the temperature (until $3 \times 10^{5}$ cycles) until the first stabilization towards approximately $245^{\circ} \mathrm{C}$, followed by a cooling and a new stabilization towards a temperature of $228^{\circ} \mathrm{C}$ after approximately $4 \times 10^{6}$ cycles. At the beginning of test, the mechanical energy dissipated into heat generates an increase in the specimen temperature. After a few seconds, a stationary regime is reached in which there is a balance between this heat source and the energy lost by conduction and convection. The temperature remains homogeneous in the specimen throughout the test duration. The first stabilization corresponds to a domain where there is microplastic strain and a martensitic transformation that is exothermic. After approximately $2 \times 10^{6}$ cycles, this transformation ends and the dissipated power decreases. The temperature decreases then slightly and is again stabilized.

A second test was carried out with a stress amplitude of $335 \mathrm{MPa}$. During this test the fracture takes place at $8.37 \times 10^{7}$ cycles. Fig. 3 shows the maximum temperature evolution on the specimen surface near the end of the test. It is noted that an abrupt increase in this temperature occurs just before the fracture. The thermographs of Fig. 4 show the temperature fields on the specimen surface at various moments from Fig. 3. The increase in the temperature is and becomes increasingly heterogeneous when one approaches the fracture.

It is supposed that just before the fracture, this local increase in the temperature is associated with the propagation of a fatigue crack in the specimen. At each cycle the plastic strain at the crack tip creates a mobile heat source in the specimen which depends on time. The temperature variation associated with this heat source is then observed by the infrared camera. A postmortem observation of the fracture surface (Fig. 5) highlights a fish eye which is characteristic of the propagation of a circular crack during VHCF fracture. In Fig. 5, it is possible to characterize the position of the inclusion which initiated crack propagation. Fig. 6 shows an observation by scanning electronic microscopy of the inclusion in the center of the fatigue crack. From Figs. 5 and 6 we can then estimate, on the one hand, the eccentricity $e=0.81$ defined as the ratio of the distance between the center of the specimen and the center of the inclusion which initiated the crack to the specimen radius, and on the other hand, the average size of inclusion $a_{\text {int }}=7.6 \mu \mathrm{m}$. We can also quantify the crack radius $a_{R}=0.285 \mathrm{~mm}$ when the crack reaches the surface of the specimen.

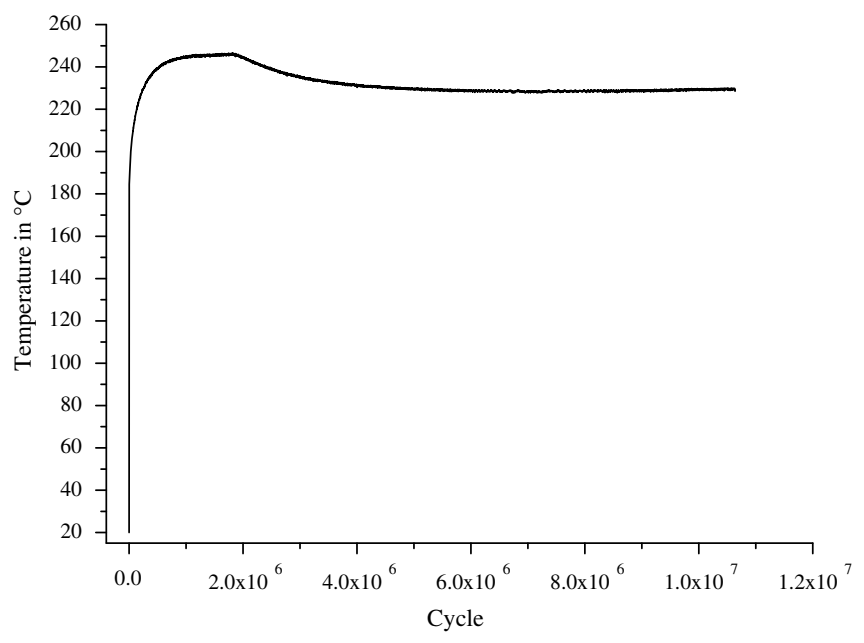

Fig. 2. Temperature evolution on the specimen surface during ultrasonic fatigue test without fracture $(\Delta \sigma=315 \mathrm{MPa})$.

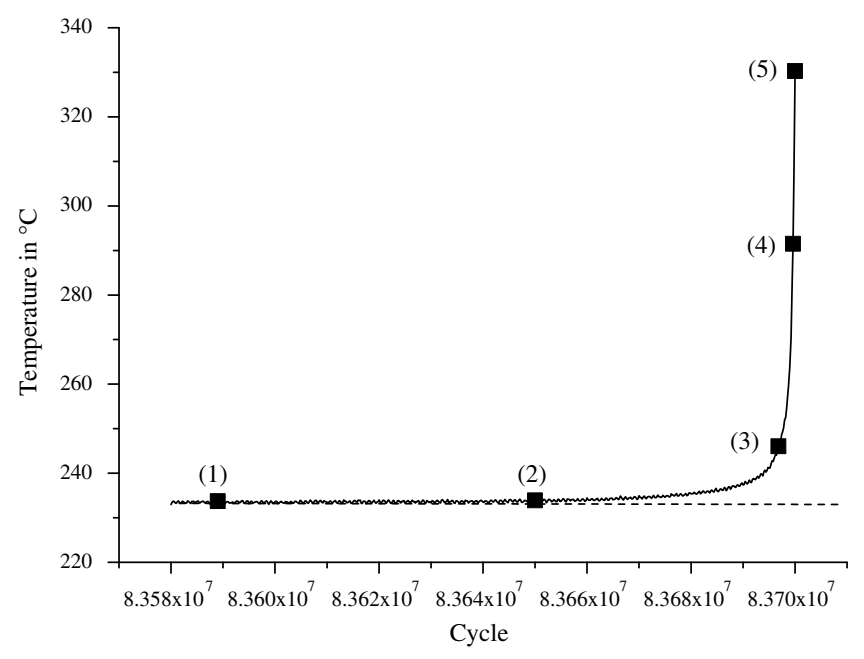

Fig. 3. Temperature evolution on the specimen surface just before fracture $\left(\Delta \sigma=335 \mathrm{MPa} ; N_{\mathrm{F}}=8.37 \times 10^{7}\right.$ cycles $)$.

\section{Modeling and discussion}

The objective of this discussion is to predict the thermal effects associated with the propagation of the fatigue crack by using the crack propagation models available in the literature. Indeed, several recent works have modeled the initiation of fish eye fatigue crack propagation from an internal defect (inclusion or porosity) [2,13-15]. The results obtained for the temperature fields will be compared with the experiment.

\subsection{The model of crack propagation}

In order to describe the growth of the fatigue crack in the case of VHCF, the Paris-Hertzberg-McClintock crack growth rate law $[13,2]$ is used 


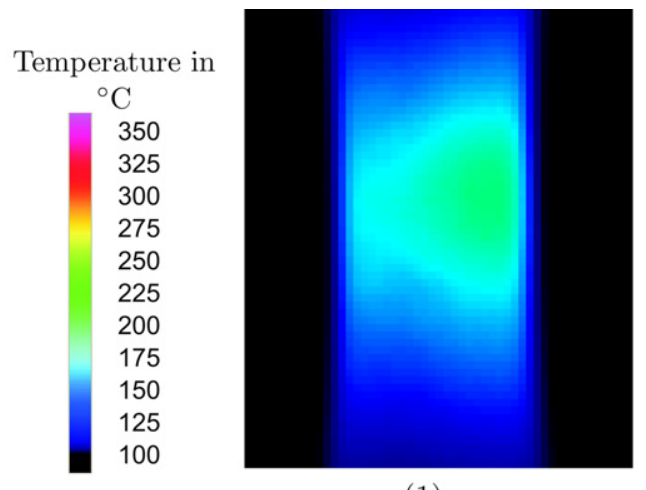

(1)

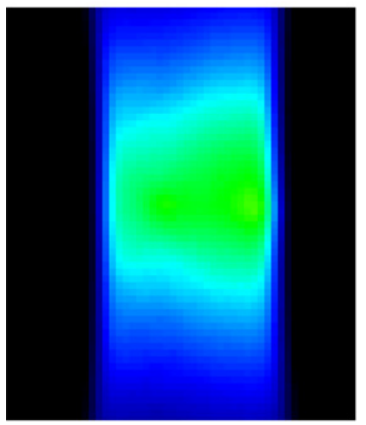

(3)

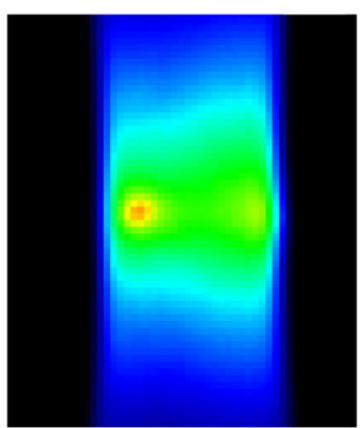

(4)

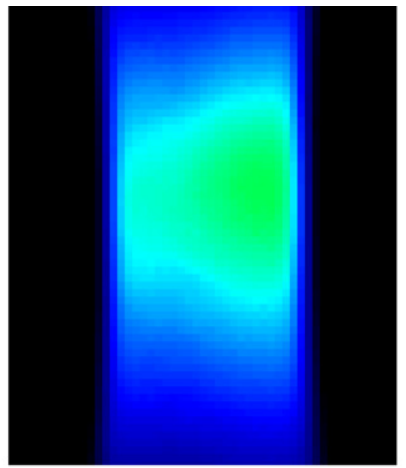

$(2)$

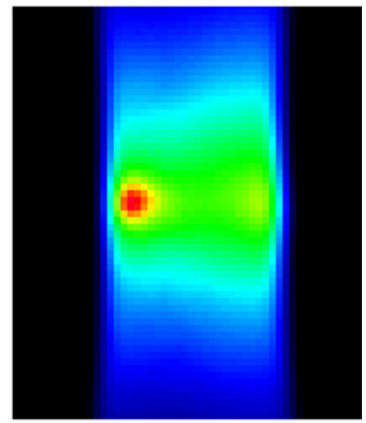

(5)

Fig. 4. Temperature fields on the specimen surface just before fracture $\left(\Delta \sigma=335 \mathrm{MPa}, N_{\mathrm{F}}=8.37 \times 10^{7}\right.$ cycles $)$. (1) $N=8.35890 \times 10^{7}$ cycles, $(2)$ $N=8.36500 \times 10^{7}$ cycles, (3) $N=8.36968 \times 10^{7}$ cycles, (4) $N=8.36996 \times 10^{7}$ cycles, and (5) $N=8.37000 \times 10^{7}$ cycles.

$\frac{\mathrm{d} a}{\mathrm{~d} N}=b\left(\frac{\Delta K_{\mathrm{eff}}}{E \sqrt{b}}\right)^{3}$

where $E$ is the Young's modulus, $b$ is the norm of the Burgers vector and $\Delta K_{\text {eff }}$ is the amplitude of the effective stress

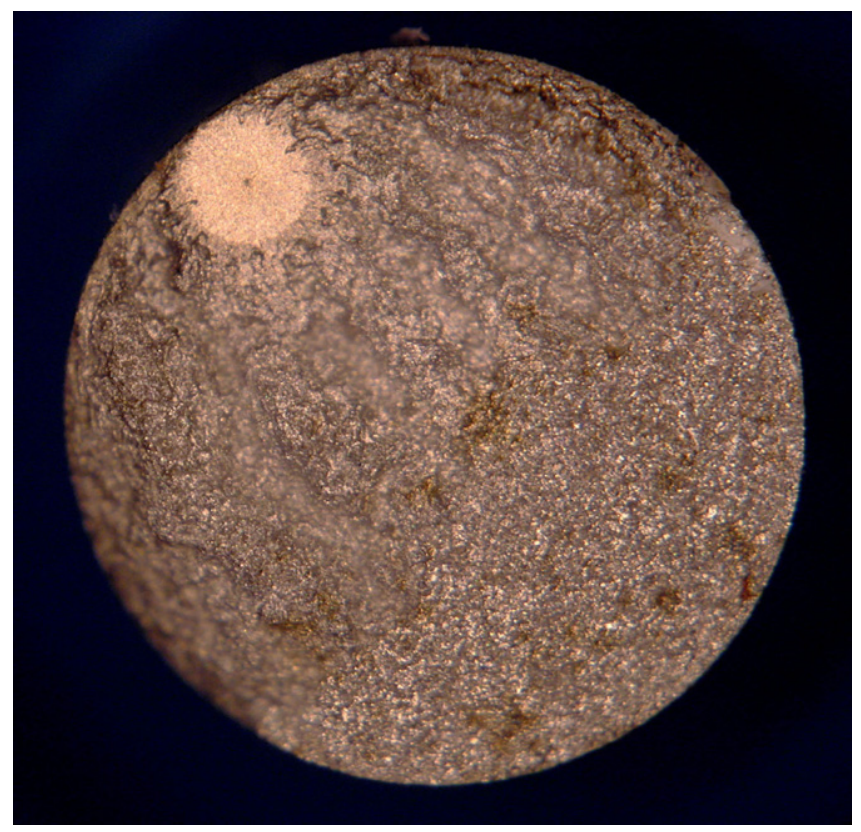

Fig. 5. Postmortem observation by optical microscopy of the fracture surface: propagation of a fish eye fatigue crack. intensity factor. This law is particularly well adapted to the formation of a fish eye because it takes into account the crack threshold, the influence of the $R$ ratio and the short crack effect.

This paper will not consider the short crack to long crack transition and will use only the short crack growth rate law. Ref. [14] showed that this assumption has a negligible influence on the prediction of the cycles corresponding to the start of the fish eye crack growth.

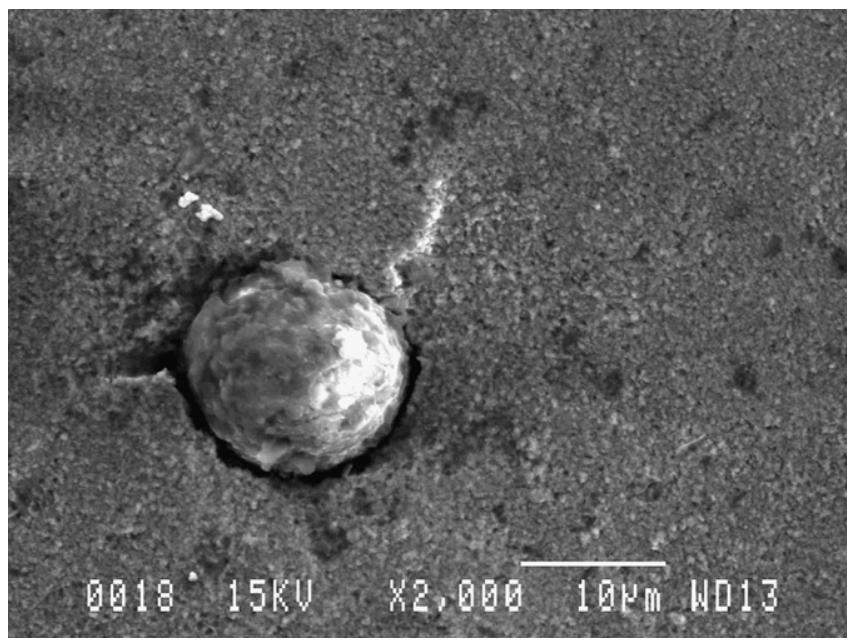

Fig. 6. Observation by scanning electron microscopy of the inclusion in the center of the fatigue crack. 


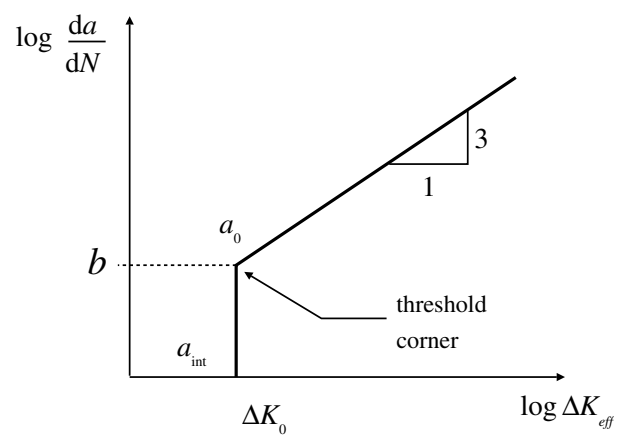

Fig. 7. Crack growth rate according to the stress intensity factor.

On the threshold corner (Fig. 7), we have

$\frac{\mathrm{d} a}{\mathrm{~d} N}=b \quad$ and $\quad \frac{\Delta K_{0}}{E \sqrt{b}}=1$.

The crack growth rate law is thus written

$\frac{\mathrm{d} a}{\mathrm{~d} N}=b\left(\frac{\Delta K_{\text {eff }}}{E \sqrt{b}}\right)^{3}=b\left(\frac{\Delta K_{0}}{E \sqrt{b}}\right)^{3}\left(\frac{\Delta K_{\text {eff }}}{\Delta K_{0}}\right)^{3}=b\left(\frac{\Delta K_{\text {eff }}}{\Delta K_{0}}\right)^{3}$.

By supposing a circular crack and neglecting the crack closure, we obtain

$\Delta K_{\text {eff }}=\Delta K=\frac{2}{\pi} \Delta \sigma \sqrt{\pi a}$.

Therefore

$\frac{\mathrm{d} a}{\mathrm{~d} N}=b\left(\frac{a}{a_{0}}\right)^{3 / 2}$.

If at time $t=0$ the crack radius is $a_{0}$, then

$\left(\frac{a_{0}}{a}\right)^{3 / 2} \mathrm{~d} a=b f \mathrm{~d} t$,

where $f$ is the loading frequency $(\mathrm{d} N=f \mathrm{~d} t)$.

Integration of the previous equation between $a_{0}(t=0)$ and $a$ (time $t$ ) gives

$b f t=\left(a_{0}\right)^{3 / 2} \int_{a_{0}}^{a} \frac{\mathrm{d} a}{a^{3 / 2}}=\left(a_{0}\right)^{3 / 2}\left[\frac{-2}{\sqrt{a}}\right]_{a_{0}}^{a}=2 a_{0}\left(1-\sqrt{\frac{a_{0}}{a}}\right)$.

After inversion of Eq. (7), the evolution of $a$ according to time is

$a(t)=\frac{a_{0}}{\left(1-\frac{t}{t_{\mathrm{c}}}\right)^{2}} \quad$ with $t_{\mathrm{c}}=\frac{2 a_{0}}{b f}$.

In the experiment presented in the beginning of this paper, $a_{\text {int }}=7.6 \mu \mathrm{m}$ and the estimate is $a_{0}=\frac{a_{\text {int }}}{0.94}=8 \mu \mathrm{m}$ [13]. $t_{\mathrm{c}}=4.4 \mathrm{~s}$ is then obtained. The evolution of the crack radius $a(t)$ is represented in Fig. 8a. This curve presents a vertical asymptote for $t=t_{\mathrm{c}}$. When $a_{0}$ increases we assume for long life that the stress must be smaller (at threshold $\Delta K_{0}$ ), so the crack growth time gets longer.

In fact, as the specimen size is limited, the crack reaches its surface at time $t_{\mathrm{f}}$ before the characteristic time $t_{\mathrm{c}}$. We
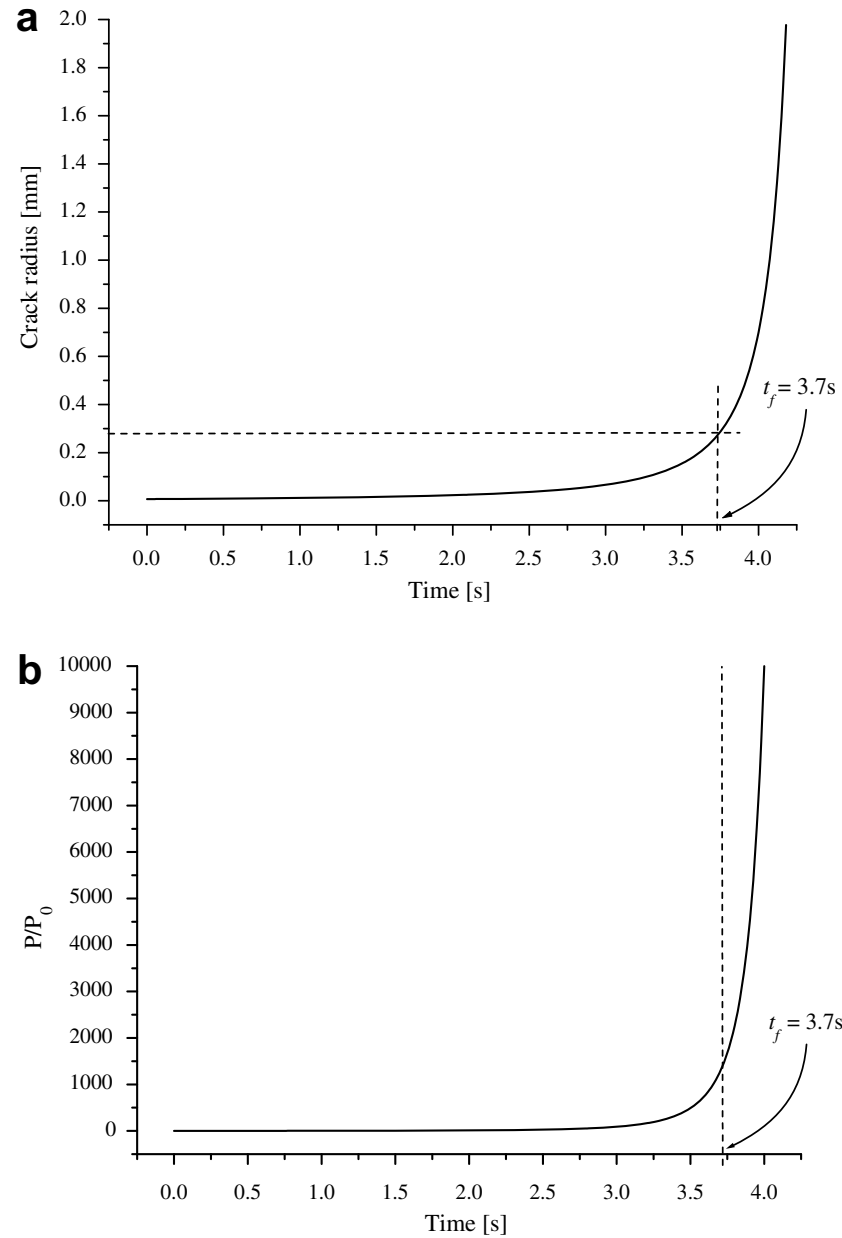

Fig. 8. Model of the crack propagation: (a) evolution of the crack radius and (b) evolution of the disspated power per unit length of crack.

will thus limit the study of the crack propagation to the time $t_{\mathrm{f}}$. The dotted lines in Fig. 8a represent the time $t_{\mathrm{f}}$ when the crack emerges on the level of the specimen surface. By replacing $a\left(t_{\mathrm{f}}\right)=R_{1}(1-e)$ in Eq. (8), we obtain a relation between $t_{\mathrm{f}}$ and $t_{\mathrm{c}}$

$t_{\mathrm{f}}=t_{\mathrm{c}}\left(1-\sqrt{\frac{a_{0}}{R_{1}(1-e)}}\right)$.

In the case of the second test with a stress amplitude of $335 \mathrm{MPa}$, we find $t_{\mathrm{f}}=3.6 \mathrm{~s}$ and a cycle number equal to $7.4 \times 10^{4}$ cycles. This shows that the crack propagation stage constitutes a very small part of the specimen life.

\subsection{Calculation of the energy dissipated into heat during crack growth}

The relation to estimate the radius of the plastic zone in the monotonic loading case of a long crack in plane strain is

$r_{\mathrm{y}}=\frac{K^{2}}{6 \pi \sigma_{\mathrm{y}}^{2}}$,

where $\sigma_{\mathrm{y}}$ is the yield stress and $K$ is the stress intensity factor. 
It is supposed that the plasticity at the crack tip always has the same distribution of strains since it is surrounded by the same elastic stress field. So, the energy dissipated at each cycle per unit of crack length, noted $\mathscr{E}$, is proportional to the surface of the reverse plastic zone, $r_{\mathrm{R}}$, with a radius of $\frac{r_{\mathrm{y}}}{4}$

$\mathscr{E}=\eta r_{\mathrm{R}}^{2} \quad$ with $r_{\mathrm{R}}=\frac{\Delta K^{2}}{24 \pi \sigma_{\mathrm{y}}^{2}}$,

where $\eta$ and $\Delta K$ are, respectively, a coefficient depending only on the material properties and the amplitude of the stress intensity factor.

By replacing the expression of $r_{\mathrm{R}}, \Delta K$ in Eq. (4) and $a(t)$ in Eq. (11), we obtain

$$
\mathscr{E}=\eta \frac{\Delta K^{4}}{24^{2} \pi^{2} \sigma_{\mathrm{y}}^{4}}=\eta \frac{a^{2} \Delta \sigma^{4}}{36 \pi^{4} \sigma_{\mathrm{y}}^{4}}=\eta \frac{a_{0}^{2} \Delta \sigma^{4}}{36 \pi^{4} \sigma_{\mathrm{y}}^{4}\left(1-\frac{b f t}{2 a_{0}}\right)^{4}} .
$$

We thus deduce the dissipated power per unit length of crack

$$
\mathscr{P}=\mathscr{E} f=\eta \frac{f a_{0}^{2} \Delta \sigma^{4}}{36 \pi^{4} \sigma_{\mathrm{y}}^{4}\left(1-\frac{b f t}{2 a_{0}}\right)^{4}}=\frac{\mathscr{P}_{0}}{\left(1-\frac{t}{t_{\mathrm{c}}}\right)^{4}},
$$

with $t_{\mathrm{c}}=\frac{2 a_{0}}{b f}$ and $\mathscr{P}_{0}=\eta \frac{f a_{0}^{2} \Delta \sigma^{4}}{36 \pi^{4} \sigma_{y}^{4}}$.

Fig. $8 \mathrm{~b}$ shows the evolution of the power dissipated per unit length of crack $\mathscr{P}$ according to time with the values of the parameters corresponding to the second test.

\subsection{Modeling of the thermal problem}

The useful part of the specimen is modeled by a cylinder with a radius $R=R_{1}$ and a length $2 \ell$. Further, consider a circular crack in a plane perpendicular to the specimen axis and located at the center of the specimen. The radius of the crack and its eccentricity from the center of the specimen are, respectively, noted $a(t)$ and $e$ (Fig. 9a). For symmetry reasons, consider only one half of the specimen $z>0$ (Fig. 9b).

The heat source associated with the fatigue crack is located in the reversing plastic zone at the crack tip. This zone is very small compared with the size of the specimen, and the power is considered to be dissipated along the crack tip, which is a circle centered on $O_{\mathrm{c}}$ and with a radius $a(t)$. The dissipated power per unit length of crack $\mathscr{P}$ used in this thermal model was expressed in the preceding section.

The heat transfer equation gives

$\rho C \frac{\partial T}{\partial t}=\frac{\mathscr{P}(t)}{2} \delta\left(r_{\mathrm{c}}-a(t)\right) \delta(z)+\lambda \Delta T$,

where $r_{\mathrm{c}}$ is the radius in polar coordinates in the reference $\left(O_{\mathrm{c}}, x_{\mathrm{c}}, y_{\mathrm{c}}\right), \delta$ is the Dirac function and $\Delta$ is the Laplacian operator (not so in $\Delta K$ above). $\rho$ and $C$ are, respectively, the density and the specific heat capacity.

The characteristic time of the heat convection is written for the case of a cylindrical specimen $\tau_{\mathrm{cv}}=\frac{\rho C R_{1}}{2 h}$ and is equal
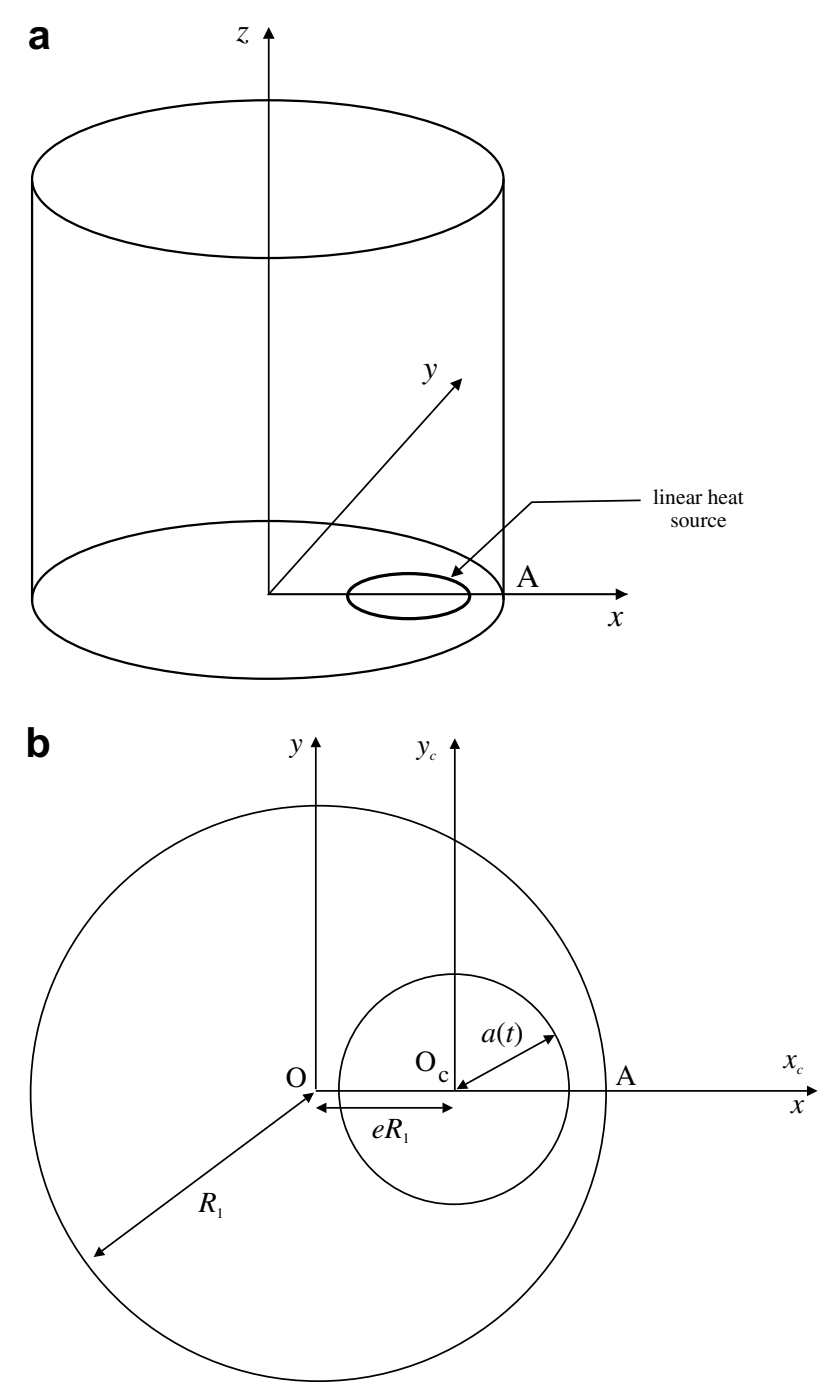

Fig. 9. Geometry of the thermal problem: (a) tridimensional visualization and (b) geometry of the circular crack.

to $13.5 \mathrm{~s}$. It is higher than the crack propagation time. The losses due to the heat convection during the propagation stage of the crack can thus be neglected and it is appropriate to consider adiabatic conditions on the surface of the specimen. Moreover, symmetry conditions on the plane $z=0$ allows adiabatic conditions on this plane to be adopted

$\lambda \frac{\partial T}{\partial r}\left(r=R_{1}\right)=0, \quad \lambda \frac{\partial T}{\partial z}(z=0)=0, \quad \lambda \frac{\partial T}{\partial z}(z=\ell)=0$.

Just before the crack propagation, a homogeneous initial temperature equal to $T_{0}$ was selected

$T(t=0)=T_{0}$.

In order to normalize dimensions in the problem, it is noted $r^{*}=\frac{r}{R_{1}}, a^{*}=\frac{a}{R_{1}}, z^{*}=\frac{z}{R_{1}}, t^{*}=\frac{\lambda t}{R_{1}^{2} \rho C}$ and $t_{\mathrm{c}}^{*}=\frac{\lambda t_{\mathrm{c}}}{R_{1}^{2} \rho C}$. This gives 
$\frac{\partial T}{\partial t^{*}}=\frac{R_{1}^{2}}{2 \lambda} \frac{\mathscr{P}_{0}}{\left(1-\frac{t^{*}}{t_{\mathrm{c}}^{*}}\right)^{4}} \delta^{*}\left(r_{\mathrm{c}}^{*}-a^{*}\right) \delta^{*}\left(z^{*}\right)+\Delta^{*} T$.

If $T^{*}=\left(T-T_{0}\right) \frac{2 \lambda}{R_{1}^{2} \mathscr{P}_{0}}$ is taken as the non-dimensional temperature, this yields the equation

$\frac{\partial T^{*}}{\partial t^{*}}=\frac{\delta^{*}\left(r_{\mathrm{c}}^{*}-a^{*}\right) \delta^{*}\left(z^{*}\right)}{\left(1-\frac{t^{*}}{t_{\mathrm{c}}^{*}}\right)^{4}}+\Delta^{*} T^{*}$.

The boundary conditions are

$\frac{\partial T^{*}}{\partial r^{*}}\left(r^{*}=1\right)=0, \quad \frac{\partial T^{*}}{\partial z^{*}}\left(z^{*}=0\right)=0, \quad \frac{\partial T^{*}}{\partial z^{*}}\left(z^{*}=\ell^{*}\right)=0$.

And the initial condition is

$T^{*}\left(t^{*}=0\right)=0$.

\subsection{Numerical study of the temperature field}

The thermal problem defined in the preceding section is now solved numerically by the finite-element method. Only the part located above the crack propagation plane is modeled. The finite-elements used are linear and the integration scheme is implicit. The mesh is more refined in the zone close to the plane of crack propagation: approximately 100 elements are placed on the radius of the specimen. The radius $R_{1}$ of the specimen is taken equal to $1.5 \mathrm{~mm}$ and its half length is taken equal to five times the radius.

Several calculations were made with various values of initial radius of the crack $a_{0}$ and eccentricity $e$. Table 1 sums up the calculations carried out with the values of the various parameters and their respective non-dimensionalized values. Furthermore, calculations were carried forward from the time $t_{\mathrm{f}}$ from which the crack emerges on the surface of the specimen. All these values are calculated by using the numerical values of the physical properties of material and the geometrical characteristics detailed in Table 2.

Fig. 10 shows the temperature field in the specimen at various times just before fracture. These various times are represented on the maximum temperature curve in Fig. 11. The value of $a_{0}$ is $10 \mu \mathrm{m}$ and the eccentricity is equal to 0.5. The various temperature fields in Fig. 10 highlight the thermal effects associated with the fatigue crack propagation.
Table 2

Numerical properties of the material

\begin{tabular}{ll}
\hline Parameter & Value \\
\hline$\rho$ & $7800 \mathrm{~kg} \mathrm{~m}^{-3}$ \\
$C$ & $460 \mathrm{~J} \mathrm{~K}^{-1} \mathrm{~kg}^{-1}$ \\
$\lambda$ & $52 \mathrm{~W} \mathrm{~K}^{-1} \mathrm{~m}^{-2}$ \\
$b$ & $1.8 \times 10^{-10} \mathrm{~m}$ \\
$R_{1}$ & $1.5 \mathrm{~mm}$ \\
$f$ & $20,000 \mathrm{~Hz}$ \\
\hline
\end{tabular}

The thermal calculation also allows a study of the influence of parameters such as eccentricity and initial size of the crack on the maximum temperature reached on the specimen surface. Fig. 12 shows the effect of the initial inclusion size $a_{0}$ on the temperature evolution at point $\mathrm{A}$ located at the specimen surface (see Fig. 9b) for an eccentricity of 0.5 . The increase in $a_{0}$ creates an increase in characteristic time $t_{\mathrm{c}}$ and thus in the propagation duration of the crack. The significant increase in the temperature thus takes place later when $a_{0}$ increases. It is also noticed that the maximum temperature reached decreases when $a_{0}$ increases. This is explained by the fact that when the crack emerges on the specimen surface, it dissipates less energy when the ratio $\frac{t_{\mathrm{f}}}{t_{\mathrm{c}}}$ decreases and thus when $a_{0}$ increases.

Fig. 13 shows the effect of the eccentricity $e$ on the temperature evolution at point $\mathrm{A}$ for an initial crack radius of $10 \mu \mathrm{m}$. When the eccentricity increases, the time $t_{\mathrm{f}}$ decreases and thus the power dissipated by the crack decreases. This effect causes a reduction in the maximum temperature reached on the specimen surface.

These various results show that the thermal effects associated with the crack propagation are more significant when $a_{0}$ and $e$ are small. In this case, the technique of measuring the temperature field on the specimen surface will be much better at detecting, for example, crack initiation.

\section{Discussion}

One simulation was carried out with the parameters measured during the experiment presented in Section 2 $\left(a_{0}=8 \mu \mathrm{m}\right.$ and $e=0.8$ ). A minimization via the leastsquares method of the difference between the evolution of the maximum temperature measured in experiments and the temperature obtained in the model allows the power dissipated by the crack, noted $\mathscr{P}_{0}$, to be calculated. It is found to be $\mathscr{P}_{0}=1.269 \times 10^{6} \mathrm{~W} \mathrm{~m}^{-1}$. In addition, Fig. 14

Table 1

Numerical simulation

\begin{tabular}{llllllrr}
\hline Reference & $a_{0}$ in $\mu m$ & $e$ & $t_{\mathrm{c}}$ in $\mathrm{s}$ & $t_{\mathrm{f}}$ in $\mathrm{s}$ & $a_{0}^{*}$ & $t_{\mathrm{c}}^{*}$ & $t_{\mathrm{f}}^{*}$ \\
\hline S1 & 2 & 0.5 & 1.11 & 1.05 & $1.33 \times 10^{-3}$ & 7.16 & 6.79 \\
S2 & 5 & 0.5 & 2.78 & 2.55 & $3.33 \times 10^{-3}$ & 17.89 & 16.43 \\
S3 & 10 & 0.5 & 5.56 & 4.91 & $6.67 \times 10^{-3}$ & 35.78 & 31.65 \\
S4 & 20 & 0.5 & 11.11 & 9.30 & $1.33 \times 10^{-2}$ & 71.57 & 59.88 \\
S5 & 20 & 0 & 11.11 & 9.83 & $1.33 \times 10^{-2}$ & 71.57 & 63.31 \\
S6 & 20 & 0.25 & 11.11 & 9.63 & $1.33 \times 10^{-2}$ & 71.57 & 62.03 \\
S7 & 20 & 0.75 & 11.11 & 8.55 & $1.33 \times 10^{-2}$ & 71.57 & 55.04 \\
\hline
\end{tabular}




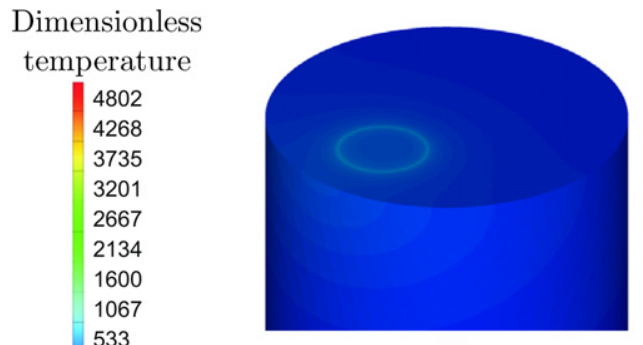

(1)

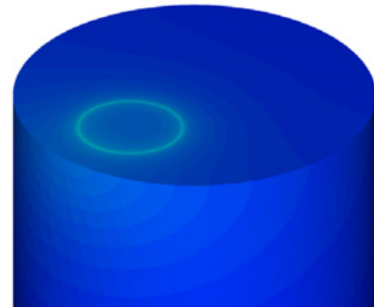

(2)

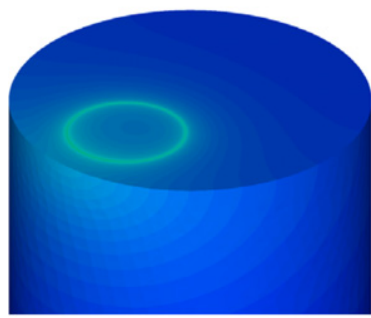

(3)

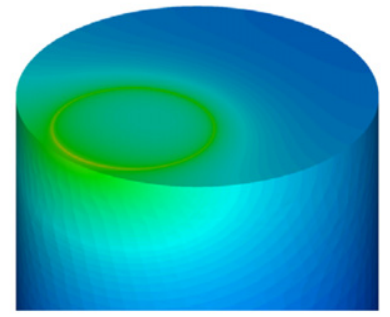

(6)

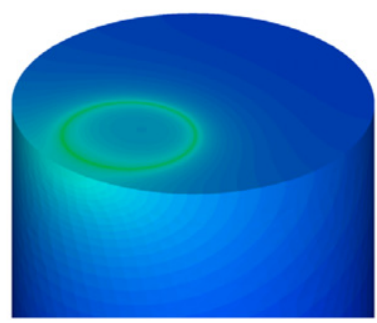

(4)

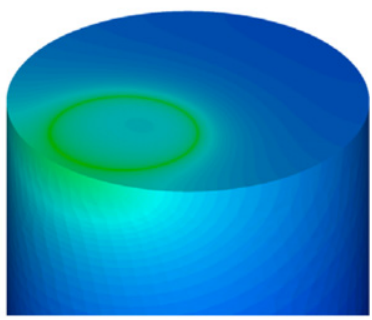

(5)

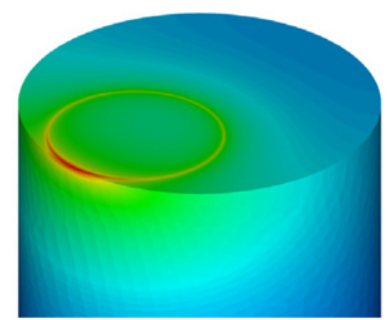

(7)

Fig. 10. Numerical simulation of the temperature field in the specimen for various times before fracture $\left(a_{0}=10 \mu \mathrm{m}, e=0.5\right)$. (1) $t^{*}=29.65 ; a^{*}=0.227$, (2) $t^{*}=30.23 ; a^{*}=0.277$, (3) $t^{*}=30.59 ; a^{*}=0.317$, (4) $t^{*}=30.89 ; a^{*}=0.357$, (5) $t^{*}=31.15 ; a^{*}=0.397$, (6) $t^{*}=31.36 ; a^{*}=0.437$, and (7) $t^{*}=31.55$; $a^{*}=0.477$.

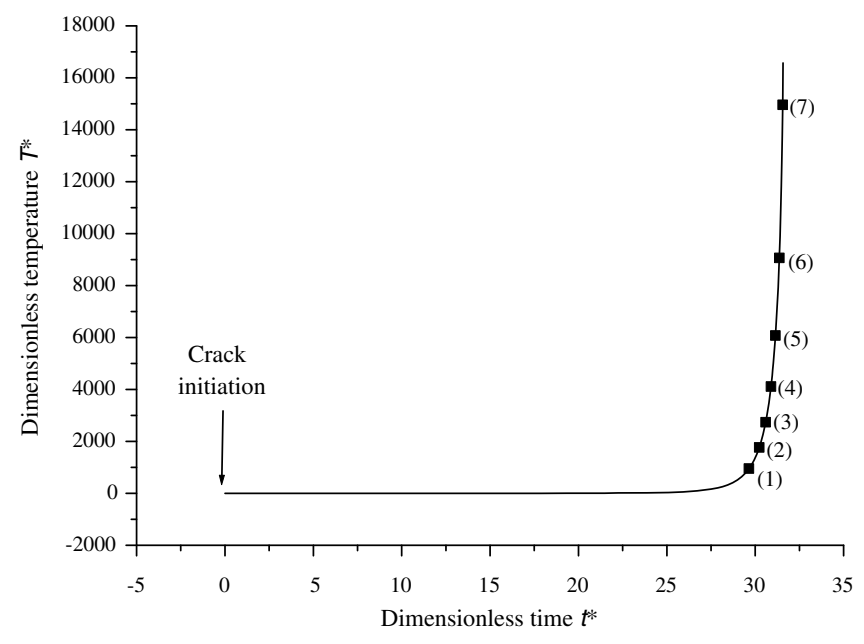

Fig. 11. Numerical simulation of the temperature evolution at point $\mathrm{A}$ on the specimen surface $\left(a_{0}=10 \mu \mathrm{m}, e=0.5\right)$.

shows the comparison between the model and the experiment. It can be seen that the model predicts correctly the shape of the temperature evolution curve. Moreover, the

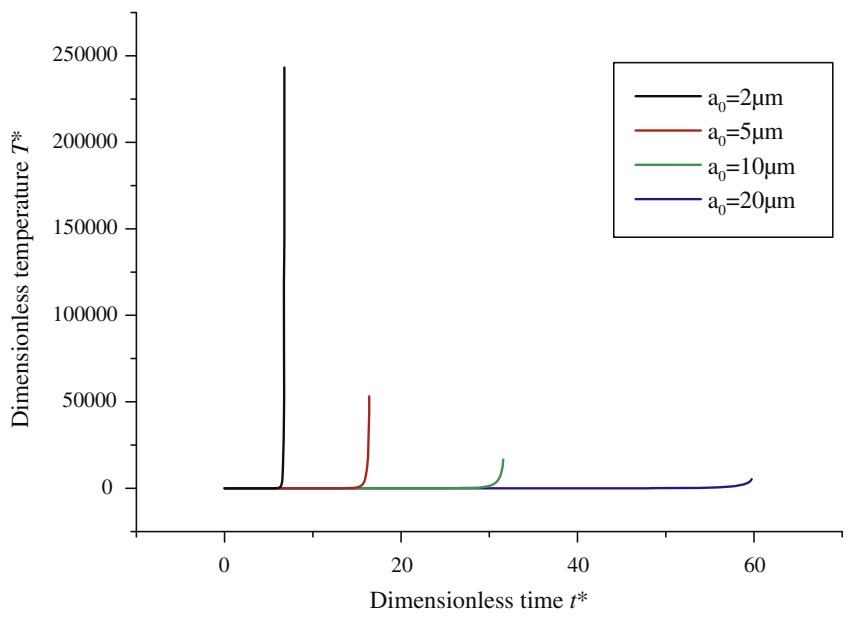

Fig. 12. Effect of the initial radius of the crack on the temperature evolution $(e=0.5)$.

model gives a good estimation of the cycle number corresponding to fish eye formation.

These results confirm the idea that around the flaw the temperature increase is very small for a very high number 


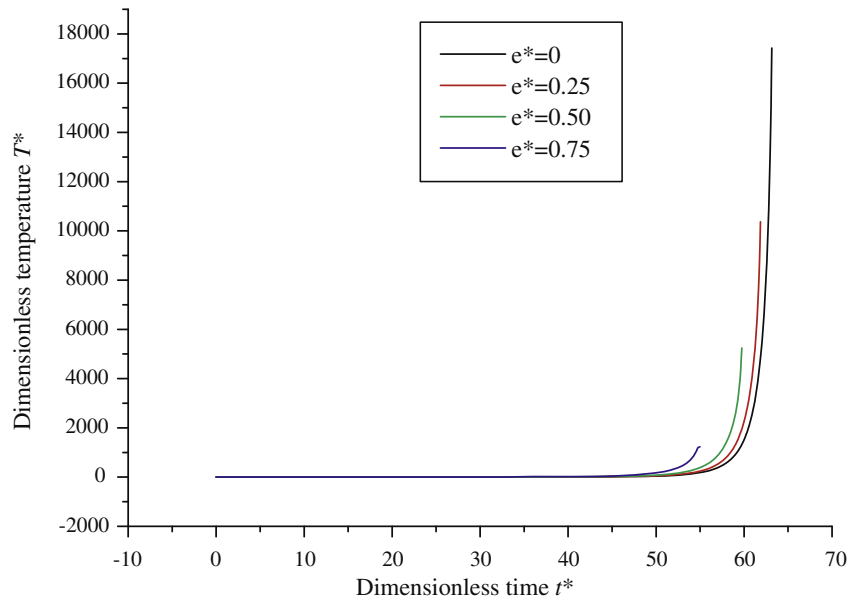

Fig. 13. Effect of eccentricity on the temperature evolution $\left(a_{0}=20 \mu \mathrm{m}\right)$.

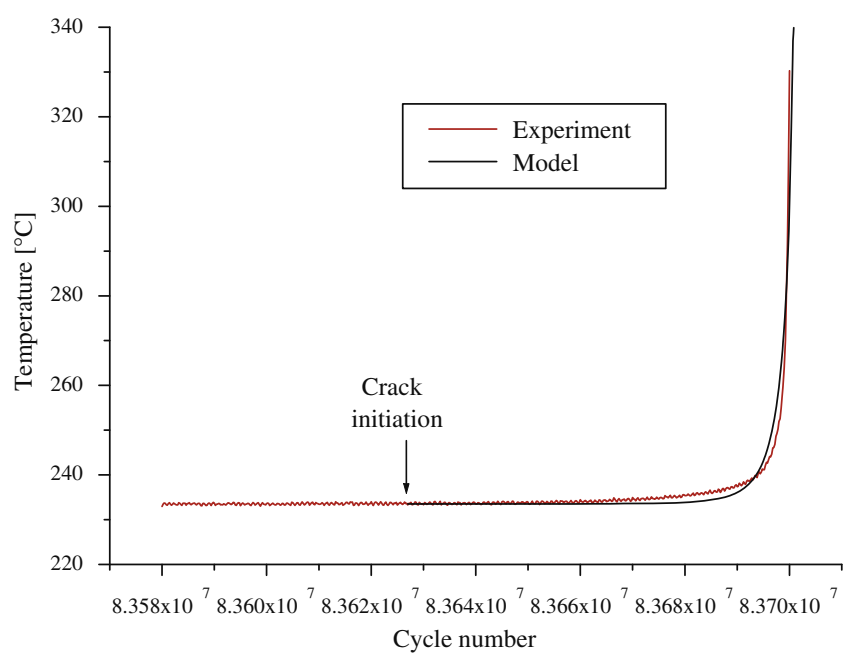

Fig. 14. Comparison between model and experiment.

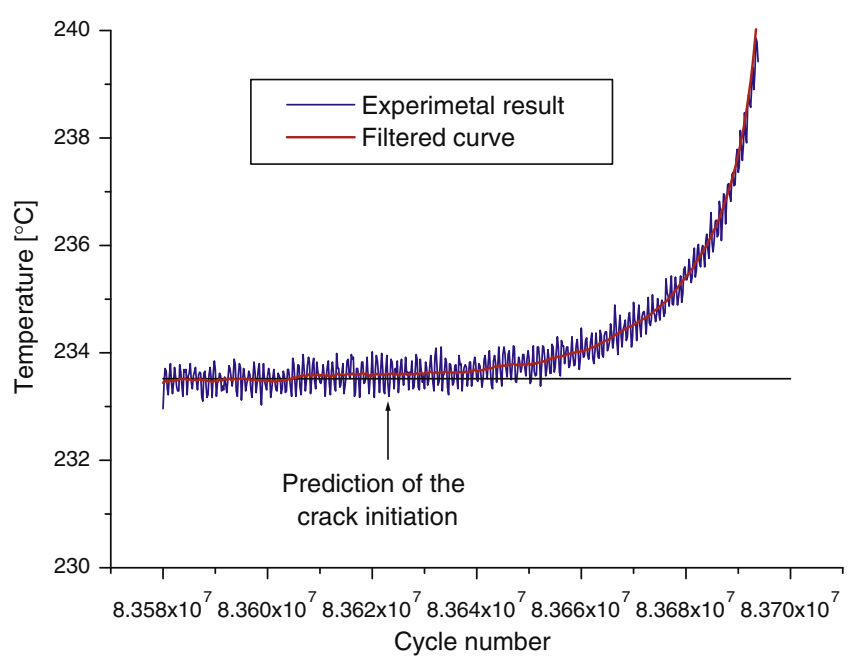

Fig. 15. Experimental determination of crack initiation. of cycles due to dislocation multiplication and permanent slip band formation with large heterogeneous mechanisms, up to a crack length $a_{0}$. From $a_{0}$ to $a_{\mathrm{f}}$, the plastic deformation is localized around a uniform circular crack tip. The thermal dissipation is quite small at $a_{0}$ but it grows faster depending on $\Delta K^{4}$.

Fig. 15 represents a close up of the experimental curve of the temperature evolution. The noise of the camera is about $0.4^{\circ} \mathrm{C}$. In order to obtain a weaker noise of $0.07^{\circ} \mathrm{C}$, the temperature signal was filtered. If crack initiation is experimentally defined as an increase in $0.07^{\circ} \mathrm{C}$ of the filtered temperature (a variation in the signal/noise ratio of 1), the experimentally determined crack initiation occurs between $8.361 \times 10^{7}$ and $8.363 \times 10^{7}$ cycles. This corresponds to a cycle number associated with crack propagation ranging between $7 \times 10^{4}$ and $9 \times 10^{4}$ cycles. The thermal model shows that a temperature variation of $0.07{ }^{\circ} \mathrm{C}$ corresponds to a crack of radius $a$ of $0.02 \mathrm{~mm}$ and a formation of only $7 \%$ of the fish eye. These results show clearly that an experimental determination of propagation of the fatigue crack in a VHCF regime corresponds to a very small part of the life of the specimen.

\section{Conclusion}

This paper studies the thermal effects associated with the propagation of a fatigue crack in a gigacycle fatigue regime. Ultrasonic fatigue tests were carried out on a high-strength steel. The temperature fields on the specimen surface were measured by infrared thermography. Just before fracture, the thermographs show a significant and very local increase in the temperature. In order to better understand these thermal effects and to make a connection with the initiation and the propagation of the fatigue crack, a thermomechanical model is developed. The Paris-Hertzberg-McClintock law was used to describe the evolution of the growth rate law of the crack. The fatigue crack is modeled by a circular ring heat source whose radius increases with time. The numerical resolution of the thermal problem allows determination of the time evolution of the temperature fields in the specimen. Comparison between test and model shows a good correlation. In particular, the propagation duration of the crack is accurately estimated by the model. These results give an experimental proof that in a VHCF regime, the propagation stage of the crack constitutes a small part of the lifetime of the specimen.

\section{Acknowledgements}

The authors thank Claude Bathias for his contribution. We are very grateful to Francisco Chinesta and Lounes Illoul for their help on the numerical calculation and Patrick Ribot for his help on the SEM observations.

\section{References}

[1] Mughrabi H. Int J Fatig 2006;28:1501. 
[2] Bathias C, Paris PC. Gigacycle fatigue in mechanical practice. New York: Marcel Dekker; 2005.

[3] Luong MP. Mech Mater 1998;28:155.

[4] Liaw PK, Wang H, Jiang L, Yang B, Huang JY, Kuo RC, et al. Scripta Mater 2000;42:389.

[5] Yang B, Liaw PK, Wang H, Jiang L, Huang JY, Kuo RC, et al. Mater Sci Eng A 2001;314:131.

[6] Fargione G, Geraci A, La Rosa G, Risitano A. Int J Fatig 2002;24:11.

[7] Curà F, Curti G, Sesana R. Int J Fatig 2005;27:453.

[8] Boulanger T, Chrysochoos A, Mabru A, Galtier A. Int J Fatig 2004:26:221.

[9] Meneghetti G. Int J Fatig 2007;29:81.

[10] Morabito AE, Chrysochoos A, Dattoma V, Galietti U. Int J Fatig 2007;29:977.
[11] Thomson W. Trans R Soc 1853;20:261.

[12] Peyroux R, Chrysochoos A, Licht C, Löbel M. Int J Eng Sci 1998;36:489.

[13] Paris PC, Marines-Garcia I, Hertzberg RW, Donald JK. The relationship of effective stress intensity, elastic modulus and Burgers vector on fatigue crack growth as associated with "fish-eye" gigacycle phenomena. In: Sakai T, Ochi Y, editors. Proceedings of the third international conference on very high-cycle fatigue. Kyoto, Japan: The Society of Materials Science; 2004. p. 1.

[14] Marines-Garcia I, Paris PC, Tada H, Bathias C, Lados D. Fatigue crack growth from small to large cracks in gigacycle fatigue with fish eye failures. In: 9th International fatigue congress, Atlanta, GA; 2006.

[15] Marines-Garcia I, Paris PC, Tada H, Bathias C. Int J Fatig 2007;29:2072 